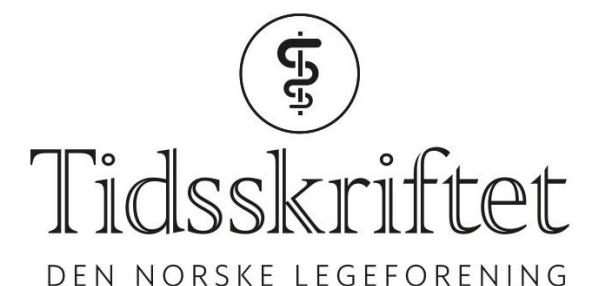

\title{
Mikrokultur av reproduksjonsorganer
}

FRA ANDRE TIDSSKRIFTER

HAAKON B. BENESTAD

Universitetet i Oslo

Kulturer av vevsbiter fra reproduksjonsorganer hos mus kan simulere menstruasjonssyklusen over flere uker.

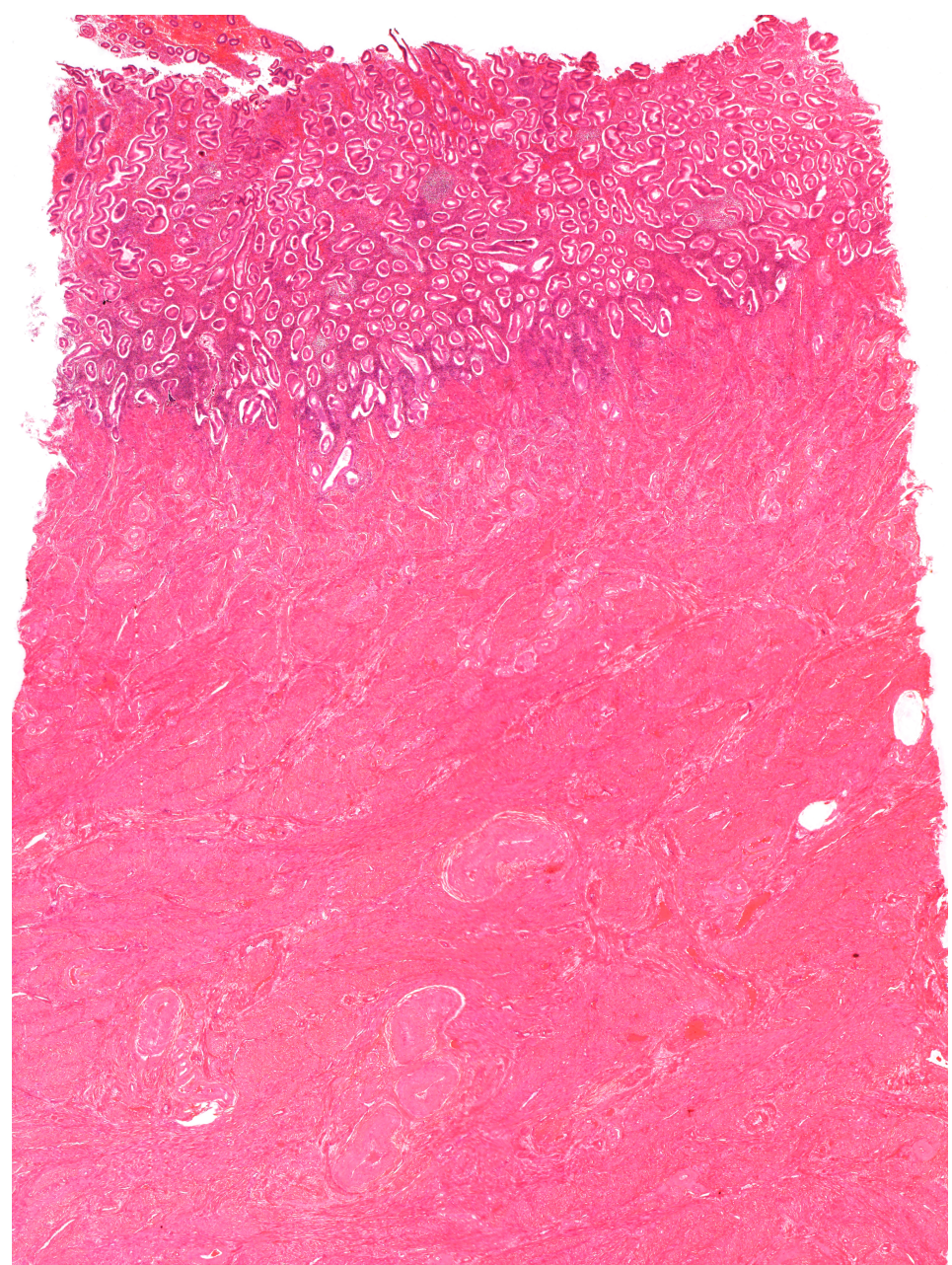

Lysmikroskopibilde av del av livmor hos menneske. Foto: Science Photo Library

Vevsbiter uten blodforsyning kan holdes i live i kultur hvis vevsvolumet er svært lite. Dette viser en ny studie som nylig er publisert i tidsskriftet Nature Communications (1). 
Fragmenter av ovarier, tubevegg, uterus og cervix fra mus ble dyrket i hvert sitt mikrokammer. Der ble de overrislet av et dyrkningsmedium fra et reservoar via rør mellom de seriekoblede kamrene med kun 100 mikroliter per time. Rørene hadde ventiler og kunne komprimeres og dilateres av elektromagnetiske stempler, som dermed ga en peristaltikklignende væskestrøm styrt fra en datamaskin. Oppsettet tillot resirkulasjon, slik at for eksempel hormoner laget i ett kammer kunne påvirke funksjonen i en vevsbit dyrket oppstrøms.

Kulturene ble eksponert for follikelstimulerende hormon i 14 dager, deretter for choriongonadotropin (i stedet for luteinstimulerende hormon). Follikler modnet og ovulerte og granulosaceller differensierte til lutealceller. Oppsettet tillot oppsamling og analyse av små væskemengder. Østrogen ble utskilt i første del av «menstruasjonssyklus», mens progesteron ble utskilt etter eggløsningen - begge med høyere sekresjonsrate enn $\mathrm{i}$ stasjonære kulturer. Humant tubevev overlevde også godt, og cilier slo etter 21 dagers dyrking, noe som ble dokumentert med videoopptak.

- Denne studien viser at kulturer av deler av reproduksjonsorganene fra hunnmus kan holdes stabile over lang tid ved hjelp av en såkalt mikrofluidisk chip-plattform, sier Stefan Krauss, som er professor og leder et nytt senter for fremragende forskning ved Institutt for medisinske basalfag, Universitetet i Oslo. Ved senteret skal man konsentrere seg om slike dyrkingsmetoder som den aktuelle studien beskriver.

- Denne studien er et viktig skritt på veien mot en metode som over tid kan supplere og kanskje erstatte eksisterende dyremodeller, sier Krauss.

\section{LITTERATUR:}

1. Xiao S, Coppeta JR, Rogers HB et al. A microfluidic culture model of the human reproductive tract and 28-day menstrual cycle. Nat Commun 2017; 8: 14584. [PubMed][CrossRef]

Publisert: 18. september 2017. Tidsskr Nor Legeforen. DOI: 10.4045/tidsskr.17.056o

(C) Tidsskrift for Den norske legeforening 2020. Lastet ned fra tidsskriftet.no 